\title{
More severe cellular phenotype in human idiopathic dilated cardiomyopathy compared to ischemic heart disease
}

\author{
Nazha Hamdani • Attila Borbély • Sophie P. G. R. Veenstra • Viola Kooij • \\ Wim Vrydag · Ruud Zaremba $\cdot$ Cris dos Remedios • Hans W. M. Niessen • \\ Martin C. Michel · Walter J. Paulus • Ger J. M. Stienen · Jolanda van der Velden
}

Received: 9 August 2010/ Accepted: 19 November 2010/Published online: 4 December 2010

(C) The Author(s) 2010. This article is published with open access at Springerlink.com

\begin{abstract}
Activation of the $\beta$-adrenergic receptor ( $\beta$ AR) pathway is the main mechanism of the heart to increase cardiac output via protein kinase A (PKA)-mediated phosphorylation of cellular target proteins, and perturbations therein may contribute to cardiac dysfunction in heart failure. In the present study a comprehensive analysis was made of mediators of the $\beta$ AR pathway, myofilament properties and cardiac structure in patients with idiopathic (IDCM; $\mathrm{n}=13$ ) and ischemic (ISHD; $\mathrm{n}=10$ ) cardiomyopathy in comparison to non-failing hearts (donor; $\mathrm{n}=10$ ) for the following parameters: $\beta$ AR density, G-coupled receptor kinases 2 and 5, stimulatory and inhibitory G-proteins, phosphorylation of myofilament
\end{abstract}

N. Hamdani · A. Borbély · S. P. G. R. Veenstra · V. Kooij

R. Zaremba · W. J. Paulus · G. J. M. Stienen ·

J. van der Velden $(\bowtie)$

Laboratory for Physiology, Institute for Cardiovascular Research

(ICaR-VU), VU University Medical Center Amsterdam,

van der Boechorststraat 7, 1081 BT Amsterdam,

The Netherlands

e-mail: j.vandervelden@vumc.nl

H. W. M. Niessen

Department of Pathology, Institute for Cardiovascular Research,

VU University Medical Center Amsterdam, Amsterdam,

The Netherlands

C. dos Remedios

Muscle Research Unit, Institute for Biomedical Research,

The University of Sydney, Sydney, Australia

W. Vrydag · M. C. Michel

Department of Pharmacology and Pharmacotherapy,

Academic Medical Center, University of Amsterdam,

Amsterdam, The Netherlands targets of PKA, protein phosphatase 1, phospholamban, SERCA2a and single myocyte contractility. All parameters exhibited the expected alterations of heart failure, but for most of them the extent of alteration was greater in IDCM than in ISHD. Histological analysis also revealed higher collagen in IDCM compared to ISHD. Alterations in the $\beta$ AR pathway are more pronounced in IDCM than in ISHD and may reflect sequential changes in cellular protein composition and function. Our data indicate that cellular dysfunction is more severe in IDCM than in ISHD.

Keywords $\beta$-Adrenergic receptor · Protein phosphorylation - Myofilament function · Cardiomyocyte . Collagen

\section{Introduction}

During increased cardiac stress stimulation of the $\beta$-adrenergic receptors ( $\beta \mathrm{AR})$ exerts a positive inotropic and lusitropic effect on the heart, via activation of protein kinase A (PKA)-mediated phosphorylation of $\mathrm{Ca}^{2+}$-handling and contractile proteins (Bers 2002; Brodde and Michel. 1999; Kranias et al. 1985; Kentish et al. 2001; Zhang et al. 1995). The positive inotropic effect largely originates from increased cytosolic $\left[\mathrm{Ca}^{2+}\right]$ during the systolic phase of the cardiac cycle. The positive lusitropic effect results from increased cytosolic $\mathrm{Ca}^{2+}$ re-uptake into the sarcoplasmic reticulum, increased $\mathrm{Ca}^{2+}$ removal out of the cardiomyocyte, and desensitization of the myofilaments for $\mathrm{Ca}^{2+}$. In patients with heart failure (HF) the sympathetic nervous system is chronically activated to maintain perfusion of vital organs via peripheral vasoconstriction and via an increase in heart rate and in myocardial contractility. Although aimed at maintaining cardiac pump 
function, chronic neurohumoral stimulation is detrimental for cardiac function and results in uncoupling and downregulation of mediators of the $\beta$ AR pathway (Brodde and Michel 1999; Packer 1995). Abnormalities in this pathway have been implicated as important determinants of diminished function of the failing human heart. The adverse effects of neurohumoral overstimulation is illustrated by the negative correlation between noradrenaline plasma levels and prognosis of the patients (Cohn et al. 1984), and by the improvement of symptoms and prolonged survival of patients treated with $\beta$-blockers (Bohm and Maack 2000). In line with reduced $\beta$-adrenergic signaling, previous studies in end-stage HF patients with idiopathic cardiomyopathy showed reduced PKA-mediated phosphorylation of downstream myofilament target proteins, cardiac myosin binding protein $\mathrm{C}(\mathrm{cMyBP}-\mathrm{C})$ and troponin I (cTnI) (El-Armouche et al. 2007; van der Velden et al. 2003; Messer et al. 2007, 2009; Copeland et al. 2010), which coincided with increased myofilament $\mathrm{Ca}^{2+}$-sensitivity $\left(\mathrm{pCa}_{50}\right)$. In patients with diastolic heart failure (i.e., HF with preserved ejection fraction, HFPEF) hypophosphorylation of titin has been associated with increased cardiomyocyte stiffness ( $\mathrm{F}_{\text {passive }}$ ) (Borbély et al. 2009). Insight in the modifications of the $\beta$-adrenergic pathway and coincident changes in cardiomyocyte function is needed to develop targeted therapy in HF patients. In a recent study we reported diverse changes at the myocardial ultrastructural level with prominent cardiomyocyte hypertrophy in HFPEF patients and low myofibrillar density in HF patients with reduced EF (HFREF) (van Heerebeek et al. 2006). Moreover, $F_{\text {passive }}$ was higher in HFPEF than in HFREF. These cellular differences may alter responsiveness to current HF treatment, which includes $\beta$-blocker therapy. Likewise, patients with idiopathic (IDCM) and ischemic (ISHD) cardiomyopathy may show diverse cellular changes.

Although many studies investigated mediators of the $\beta$ AR signaling pathway and sarcomeric function in human heart failure, a direct comparative investigation of both in samples from IDCM and ISHD patients is lacking. Within the present study a systematic analysis was performed from the $\beta$ AR to sarcomeric protein composition and function in IDCM and ISHD patients, and compared to non-failing donor myocardium (donor). Radioligand binding studies were performed to determine $\beta$ AR density. Protein analysis included down-stream components of the adrenergic signalling cascade, the phospho-proteome of the myofilaments, and SERCA2a and phospholamban levels. Myofilament function was determined in permeabilized single cardiomyocytes. Histological analysis included cardiomyocyte diameter, collagen volume fraction and myofibrillar density.

\section{Methods}

Human ventricular tissue

Left ventricular (LV) tissue samples were obtained during heart transplantation surgery from end-stage HF patients (NYHA III-IV) with IDCM ( $\mathrm{n}=13$; 10 males, 3 females; mean age $51 \pm 2$ years $)$ or ISHD $(n=10 ; 7$ males, 3 females; mean age $51 \pm 2$ years)(Table 1). Patients were classified to idiopathic dilated cardiomyopathy when the heart showed LV dilatation and LV systolic dysfunction with no identifiable cause and in the absence of coronary artery disease, hypertension, valvular disease and congenital heart disease sufficient to cause the observed myocardial abnormality (Elliott et al. 2008). In contrast, patients with ischemic heart disease had a history of myocardial infarction and explanted hearts showed severe coronary artery disease upon pathologic inspection. Medication included angiotension-converting-enzyme inhibitors, angiotensin II receptor antagonists, diuretics, $\beta$-blockers, digoxin and anti-arrhythmic agents and did not differ between the IDCM and ISHD group. Tissue from 10 donor hearts (Table 1;8 males, 2 females; mean age $38 \pm 6$ years) served as reference for non-failing myocardium. The tissue was collected in cardioplegic solution and stored in liquid nitrogen. Samples were obtained after informed consent and with approval of the local Ethical Committee (St Vincents' Hospital Human Research Ethics Committee, Sydney, Australia: File number: H03/118; Title: Molecular Analysis of Human Heart Failure). The investigation conforms with the principles outlined in the Declaration of Helsinki (1997).

\section{Protein analysis}

\section{Radioligand binding}

Tissue samples ( $200 \mathrm{mg}$ wet weight) were thawed in icecold $1 \mathrm{mM} \mathrm{KHCO}{ }_{3}$ solution, minced with scissors and then homogenized with an Ultra-Turrax (Janke \& Kunkel, Staufen, Germany) for $10 \mathrm{~s}$ at maximum speed followed by twice $20 \mathrm{~s}$ at $2 / 3$ of maximum speed. The homogenates were centrifuged for $15 \mathrm{~min}$ at $250 \times \mathrm{g}$ and $4^{\circ} \mathrm{C}$. The supernatant was filtered through medical gauze and centrifuged for $20 \mathrm{~min}$ at $50,000 \times g$ at $4^{\circ} \mathrm{C}$. The sediment was resuspended in binding buffer $(10 \mathrm{mM}$ Tris, $154 \mathrm{mM}$ $\mathrm{NaCl}, \mathrm{pH}$ 7.4). Protein content was measured by the method of Bradford using bovine $\operatorname{IgG}$ as standard. Radioligand binding was performed as described earlier (Niclauss et al. 2006) using a $90 \mathrm{~min}$ incubation at $37^{\circ} \mathrm{C}$ with $\left[{ }^{125} \mathrm{I}\right]$ iodocyanopindolol (ICYP; specific activity $2200 \mathrm{Ci} / \mathrm{mmol}$, Perkin Elmer, Zaventem, Belgium) in a 
Table 1 Patient/heart characteristics

\begin{tabular}{|c|c|c|c|c|c|c|}
\hline & Sex & Age & cMyBP-C-P ProQ & cTnI-P ProQ & cTnI-P Phos-tag & $\mathrm{pCa}_{50}$ \\
\hline ISHD1 & Male & 47 & 0.27 & 0.20 & 0.14 & 5.69 \\
\hline ISHD2 & Male & 50 & 0.36 & 0.41 & 0.54 & 5.60 \\
\hline ISHD3 & Female & 43 & 0.42 & 0.50 & - & - \\
\hline ISHD4 & Male & 45 & 0.21 & 0.32 & - & - \\
\hline ISHD5 & Female & 54 & 0.46 & 0.67 & 0.79 & 5.41 \\
\hline ISHD6 & Male & 55 & 0.67 & 2.20 & - & 5.70 \\
\hline ISHD7 & Male & 54 & 0.40 & 1.25 & 1.70 & 5.50 \\
\hline ISHD8 & Male & 54 & 0.31 & 0.33 & 0.44 & 5.73 \\
\hline ISHD9 & Male & 50 & 0.33 & 0.21 & 1.18 & 5.45 \\
\hline ISHD10 & Male & 61 & 0.20 & 0.13 & 0.74 & 5.56 \\
\hline IDCM1 & Male & 56 & 0.30 & 0.07 & 0 & 5.65 \\
\hline IDCM2 & Male & 27 & 0.32 & 0.11 & 0 & 5.65 \\
\hline IDCM3 & Male & 53 & 0.31 & 0 & - & 5.65 \\
\hline IDCM4 & Male & 53 & 0.44 & 0.22 & 0.38 & 5.59 \\
\hline IDCM5 & Male & 53 & 0.29 & 0.64 & - & - \\
\hline IDCM6 & Male & 62 & 0.25 & 0.16 & 0.47 & - \\
\hline IDCM7 & Male & 53 & 0.18 & 0.38 & 0.46 & - \\
\hline IDCM8 & Male & 44 & 0.50 & 0.33 & 1.18 & - \\
\hline IDCM9 & Female & 50 & 0.28 & 0.16 & 0.65 & 5.65 \\
\hline IDCM10 & Male & 53 & 0.25 & 0.08 & 0.46 & 5.52 \\
\hline IDCM11 & Female & 52 & 0.18 & 0.17 & 0.51 & 5.68 \\
\hline IDCM12 & Male & 58 & 0.19 & 0.12 & 0.49 & 5.71 \\
\hline IDCM13 & Female & 45 & 0.32 & 0.10 & - & - \\
\hline DONOR1 & Male & 39 & 0.62 & 1.96 & 1.75 & 5.65 \\
\hline DONOR2 & Male & 56 & 0.69 & 2.09 & 1.94 & 5.48 \\
\hline DONOR3 & Male & 21 & 0.60 & 4.54 & 1.59 & 5.48 \\
\hline DONOR4 & Female & 37 & 0.61 & 1.11 & 1.57 & 5.44 \\
\hline DONOR5 & Male & 23 & 0.64 & 0.94 & 1.74 & 5.52 \\
\hline DONOR6 & Male & 19 & 0.75 & 1.96 & 1.97 & 5.51 \\
\hline DONOR7 & Female & 53 & 0.73 & 1.12 & 1.92 & - \\
\hline DONOR8 & Male & 13 & 0.75 & 1.75 & - & 5.43 \\
\hline DONOR9 & Male & 65 & 0.49 & 1.09 & 0.98 & 5.63 \\
\hline DONOR10 & Male & 51 & 0.57 & 1.56 & - & - \\
\hline
\end{tabular}

Age and sex of all patients and donors with the corresponding mean value for cMyBP-C and cTnI phosphorylation determined on ProQ Diamond stained gels (values in arbitrary units), for cTnI phosphorylation assessed by Phos-tag (in mol per mol cTnI) and for Ca ${ }^{2+}$-sensitivity of force

total volume of $250 \mu$ l. Non-specific binding was defined as binding in the presence of $100 \mu \mathrm{M}$ isoproterenol (Sigma-Aldrich). All experiments were performed in duplicates in 96 well plates, and incubations were terminated by rapid vacuum filtration over Whatman GF/C using a Filtermate harvester (Perkin Elmer). Each filter was washed with approximately $10 \mathrm{ml}$ of buffer. Radioactivity adherent to the filters was quantified in a Topcount NXT (Perkin Elmer) using Microsint $\mathrm{O}$ scintillator (Perkin Elmer). To determine the relative amount of $\beta_{1} \mathrm{AR}$ and $\beta_{2} \mathrm{AR}$, membranes were incubated with ICYP $(100 \mathrm{pM})$ in the presence or absence of eight concentrations (range
$10^{-10}$ to $\left.10^{-3} \mathrm{M}\right)$ of the highly selective $\beta_{1} \mathrm{AR}$ antagonist CGP 20712A (1-[2-((3-carbamoyl-4-hydroxy) phenoxy) ethylamino]-3-[4-(1-methyl-4-trifluoromethyl-2-imidazolyl) phenoxy]-2-propanol methanesulfonate).

\section{Components of the $\beta$-adrenergic receptor pathway}

Protein expression levels of G-coupled receptor kinases (GRK2 and GRK5), G-proteins $\left(\mathrm{G}_{\mathrm{s}}\right.$ and $\left.\mathrm{G}_{\mathrm{i}}\right)$ and protein phosphatase 1 (PP-1) were analyzed by one-dimensional $15 \%$ SDS-polyacrylamide gel electrophoresis (1D-PAGE) and subsequent Western blotting. Samples were applied in 
concentrations which were within the linear range of detection: $20 \mu \mathrm{g}$ for GRK2, GRK5, $\mathrm{G}_{\mathrm{s}}$ and PP-1, and $10 \mu \mathrm{g}$ for $\mathrm{G}_{\mathrm{i}}$. Blots were pre-incubated with $0.5 \%$ milk powder in TTBS (Tween-tris-buffered-saline: $10 \mathrm{mM}$ Tris- $\mathrm{HCl} \mathrm{pH}$ 7.6, $75 \mathrm{mM} \mathrm{NaCl}, 0.1 \%$ Tween) for $1 \mathrm{~h}$ at room temperature. The blots were incubated overnight at $4^{\circ} \mathrm{C}$ with primary rabbit polyclonal antibodies (Santa Cruz) against GRK2 (dilution 1:1000; sc-562), GRK5 (dilution 1:1000; sc-565), $\mathrm{G}_{\mathrm{s}}\left(\mathrm{G}_{\mathrm{s} / \mathrm{olf}}\right.$; dilution 1:1000; sc-383), $\mathrm{G}_{\mathrm{i}}$ (dilution $1: 1000 ; \mathrm{G}_{\mathrm{i}-1}$ sc-262, $\mathrm{G}_{\mathrm{i}-2} \mathrm{sc}-7276, \mathrm{G}_{\mathrm{i}-3}$ sc-262) or primary mouse polyclonal antibody against PP-1 (dilution 1:50; sc-7482, Santa Cruz). Specificity of the antibodies has been shown in previous studies (Vinge et al. 2001; Cho and Kehrl 2007) and all antibodies revealed one protein band in our Western blot analysis indicative for their specificity. Primary antibody binding was visualized using a secondary horseradish peroxidase-labeled goat-anti-rabbit/mouse antibody (dilution 1:2000; DakoCytomation) and enhanced chemiluminescence (ECL plus Western blotting detection, Amersham Biosciences). All signals were normalized to actin (dilution 1:1000; clone KJ43A; Sigma) stained on the same blots.

\section{Myofilament protein phosphorylation}

Myofilament protein phosphorylation was determined using Pro-Q Diamond Phosphoprotein Stain as described previously (Zaremba et al. 2007). To preserve the endogenous phosphorylation status, frozen biopsies were homogenized in liquid nitrogen and re-suspended in $1 \mathrm{ml}$ cold $10 \%$ trichloroacetic acid solution (TCA; dissolved in acetone containing $0.1 \%(\mathrm{w} / \mathrm{v})$ dithiothreitol (DTT)). TCAtreated tissue pellets were homogenized in sample buffer containing 15\% glycerol, $62.5 \mathrm{mM}$ Tris (pH 6.8), $1 \%$ (w/v) SDS and $2 \%(\mathrm{w} / \mathrm{v})$ DTT. Tissue samples were separated on gradient gels (Criterion tris- $\mathrm{HCl} 4-15 \%$ gel, BioRad) and proteins were stained for one hour with Pro-Q Diamond Phosphoprotein Stain. Fixation, washing and de-staining were performed according to the manufacturer's guidelines (Molecular Probes). To assess protein content subsequently gels were stained overnight with SYPRO Ruby stain (Molecular Probes). Phosphorylation status of myofilament proteins was expressed relative to protein expression of cMyBP-C to correct for differences in sample loading. Staining was visualized using the LAS-3000 Image Reader and signals were analyzed with AIDA.

Cardiac troponin I phosphorylation at PKA sites Ser 23/ 24 was detected with a primary rabbit polyclonal antibody (dilution 1:500; Cell signaling) in Western blotting. In addition, the recently developed Phos-tag ${ }^{\mathrm{TM}}$ acrylamide (FMS Laboratory; Hiroshima University, Japan) (Kinoshota et al. 2006) was used to visualize phosphorylated cTnI species using alkoxide-bridged dinuclear metal
$\left(\mathrm{Mn}^{2+}\right)$ complex as phosphate-binding tag (Phos-tag) molecule. $\mathrm{Mn}^{2+}$-Phos-tag molecules preferentially capture phosphomonoester dianions bound to Ser, Thr and Tyr residues. Non-phosphorylated and phosphorylated cTnI species were separated in 1D-PAGE with polyacrylamidebound $\mathrm{Mn}^{2+}$-Phos-tag and transferred to Western blots. Phosphorylated cTnI species in the gel are visualized as slower migration bands compared to the corresponding dephosphorylated cTnI form (Kooij et al. 2010; Messer et al. 2009).

\section{SERCA2a and phospholamban}

SERCA2a protein levels were determined immunochemically by dot-blot analysis, as described before, with minor modifications (Muller et al. 1991). Briefly, homogenized tissue samples (typically $0.5 \mu \mathrm{g}$ total protein) were spotted in triplo onto a nitrocellulose membrane. The blot was then incubated with a 1:2500 dilution of a polyclonal antiserum to SERCA2a and subsequently with 125I-labeled antirabbit immunoglobulin $\mathrm{G}(0.05 \mathrm{mg} / \mathrm{ml}$, specific activity $7 \mathrm{mCi} / \mathrm{mg}$ ). To detect phospholamban, blots were first incubated with a 1:2500 dilution of a monoclonal anti mouse antibody (Affinity Bioreagents) and subsequently with 125I-labeled anti-mouse immunoglobulin G. Blots were exposed to Phosphor Imager screens, which were then scanned and spots were quantified using ImageQuant software (Molecular Dynamics). All protein values for ISHD and IDCM samples were normalized to the average value observed in donor, which was set to 1 .

Force measurements in single cardiomyocytes

Force measurements were performed in single, mechanically isolated cardiomyocytes as described previously (Kooij et al. 2010; van der Velden et al. 2003). Tissue samples were defrosted in relaxing solution (in $\mathrm{mmol} / \mathrm{l}$ : free $\mathrm{Mg}$, 1; KCl, 145; EGTA, 2; MgATP, 4; imidazole, 10; $\mathrm{pH}$ 7.0), mechanically disrupted and incubated for $5 \mathrm{~min}$ in relaxing solution supplemented with $0.5 \%$ Triton $\mathrm{X}-100$ to remove all membrane structures. Subsequently, cells were washed twice in relaxing solution, after which single cardiomyocytes were attached with silicone adhesive between a force transducer and a motor. Sarcomere length of isolated cardiomyocytes was adjusted to $2.2 \mu \mathrm{m}$. The pCa $\left(-{ }_{10} \log \left[\mathrm{Ca}^{2+}\right]\right)$ ranged from 9.0 (relaxation solution) to 4.5 (maximal activation). All force values were normalized for cardiomyocyte cross-sectional area. Exposure to a series of solutions with intermediate $\mathrm{pCa}$ values $(\mathrm{pCa}$ 6.0-5.0) yielded the baseline force-pCa relation. On transfer of the cardiomyocyte from relaxing to activating solution, isometric force started to develop. Once a steady state force level was reached, the cell was shortened within 
$1 \mathrm{~ms}$ to $80 \%$ of its original length to determine the baseline of the force transducer. The distance between the baseline and the steady force level is the total force $\left(\mathrm{F}_{\text {total }}\right)$. After $20 \mathrm{~ms}$, the cell was restretched and returned to the relaxing solution, in which a second slack test, of $10 \mathrm{~s}$ duration was performed to determine passive force $\left(F_{\text {passive }}\right)$. Active force was obtained by subtracting passive force from the total force, i.e., $F_{\text {active }}=F_{\text {total }}-F_{\text {passive }}$.

\section{Quantitative histomorphometry}

Histomorphologic analysis of tissues was performed on elastica-von-Giesson and hematoxylin-eosin-stained $4 \mu \mathrm{m}$ thick sections of tissue fixed in 5\% formalin (Borbély et al. 2005). Images of these sections were acquired using a projection microscope $(\times 50)$. Subsequent image analysis, using SlidebookTM 4.0 software (3I, Denver, Co), was performed to determine cardiomyocyte diameter and the extent of interstitial fibrosis, which was expressed as collagen volume fraction. Areas of reparative and perivascular fibrosis were excluded. Cardiomyocyte diameter was determined perpendicularly to the outer contour of the cell membrane at nucleus level in 15 representative myocytes of the cardiac tissue section, and collagen volume fraction was calculated as the sum of all connective tissue areas divided by the sum of all connective tissue and muscle areas averaged over 4-6 representative fields of the cardiac tissue section. Data were averaged per heart sample and averaged to obtain the mean of the group. For analysis of cardiomyocyte diameter and collagen volume fraction 9 ISHD, 7 IDCM and 5 donor hearts were included.

Analysis of myofibrillar density was performed in 8 ISHD, 6 IDCM and 5 donor hearts. Tissues samples were fixed in $2 \%(\mathrm{v} / \mathrm{v})$ gluteraldehyde for $30 \mathrm{~min}$ and $1.5 \%(\mathrm{w} / \mathrm{v})$ osmium tetroxide for 10 min dehydrated with acetone and embedded in Epon812. Ultrathin sections were collected on 300-mesh Formavar-coated Nickel-grids. The sections were contrasted with uranyl acetate and lead citrate and were examined in a Jeol-1200EX electron microscope. Quantitative analysis was performed with the above mentioned automated image analyzer. Cardiomyocyte myofibrillar density was calculated from the sum of the myofibrillar areas related to total cellular area in 4-6 representative myocytes per sample. Data were averaged per heart.

\section{Data analysis}

Competition binding data were analyzed by fitting monoand biphasic sigmoidal functions to the experimental data; a biphasic fit was accepted only if it resulted in a significant improvement as judged by an F-test. Resulting $\mathrm{IC}_{50}$ values for the high and low affinity component of inhibition were converted to $\mathrm{K}_{\mathrm{i}}$ values based upon the Cheng-Prusoff equation (Cheng and Prusoff 1973) and assuming a $K_{d}$ value of ICYP of $72 \mathrm{pM}(\mathrm{n}=4)$. Due to limited tissue availability, receptor density $\left(\mathrm{B}_{\max }\right)$ was estimated based upon the specific binding (SB) of the single radioligand concentration $(\mathrm{L})$ in the competition experiments relative to its $K_{d}$ using the equation $B_{\max }=\mathrm{SB} /(1-1 /(\mathrm{L} /$ $\left.\mathrm{K}_{\mathrm{d}}+1\right)$ ). The statistical significance of inter-group differences was assessed by one-way ANOVA followed by Dunnett's post-hoc tests.

Values are given as mean \pm SEM of $n$ observations. The mean data values of protein and histological analysis and force measurements in ISHD, IDCM and donor samples were compared using one-way ANOVA and Bonferroni-post tests. $P<0.05$ was considered significant. All statistical analysis was performed with Prism (version 4.01, Graphpad Software, San Diego, CA, USA).

\section{Results}

Components of the $\beta$-adrenergic receptor pathway

In all cases except one competition by the highly $\beta_{1}$-selective antagonist CGP 20712A resulted in biphasic curves (Fig. 1a). The $-\log \mathrm{K}_{\mathrm{i}}$ values for high and low affinity sites, which identify $\beta_{1} \mathrm{AR}$ and $\beta_{2} \mathrm{AR}$, respectively, were not significantly different between IDCM ( 8 hearts; $8.21 \pm 0.19$ and $5.59 \pm 0.09)$ and ISHD (8 hearts; $8.17 \pm 0.09$ and $5.62 \pm 0.10)$ myocardium, and did not differ from the values observed in donor $(7$ hearts; $8.55 \pm 0.12$ and $5.74 \pm 0.11)$. Single point estimates of total $\beta \mathrm{AR}$ density, revealed significantly reduced $\beta \mathrm{AR}$ density in IDCM compared to donor, while the value observed in ISHD was intermediate between IDCM and donor (Fig. 1b). The percentage of $\beta_{1}$ ARs did not differ between IDCM $(50 \pm 4 \%)$ and ISHD (47 $\pm 9 \%)$ samples and was comparable to the value observed in donor $(52 \pm 6 \%)$.

No difference was found in expression of GRK2 between IDCM and ISHD, while GRK5 was significantly higher in ISHD than in IDCM myocardium (Table 2). Compared to donor GRK2 was significantly lower in both failing groups, while GRK5 was significantly higher in the ISHD group. $\mathrm{G}_{\mathrm{s}}$ expression did not differ between ISHD and IDCM, though was significantly lower in both failing groups compared to donor (Fig. 1c; Table 2). In addition to $\mathrm{G}_{\mathrm{s}}$, we have analyzed three isoforms of inhibitory G-protein: $G_{i \alpha-1}, G_{i \alpha-2}$ and $G_{i \alpha-3}$. The heterotrimeric G-proteins are composed of $\alpha, \beta$ and $\gamma$ subunits, of which the $\alpha$-subunit confers specificity to the G-protein (Wang and Dhalla 2000). $G_{i \alpha-1}$ expression was significantly higher in IDCM than in ISHD and donor (Fig. 1d), while $\mathrm{G}_{\mathrm{i} \alpha-2}$ was significantly higher in both failing groups compared to donor 
Fig. 1 a Competition curve of radioligand binding as a function of CGP 20712A. b $\beta$ AR density was significantly lower in IDCM compared to donor, but the receptor distribution was the same. c Western blot examples of $\beta$ AR pathway proteins in IDCM, ISHD and donor. Expression of Gs was significantly lower in failing compared to donor, but did not differ between IDCM and ISHD. d The expression level of $\mathrm{G}_{\mathrm{i} \alpha-1}$ was significantly increased in IDCM compared to donor, while ISHD did not differ from donor. $* P<0.05$ in Bonferronipost tests, IDCM versus ISHD; ${ }^{\#} P<0.05$, in Bonferroni-post tests, failing versus donor. Donor values obtained in Western blot analyses were set to 1
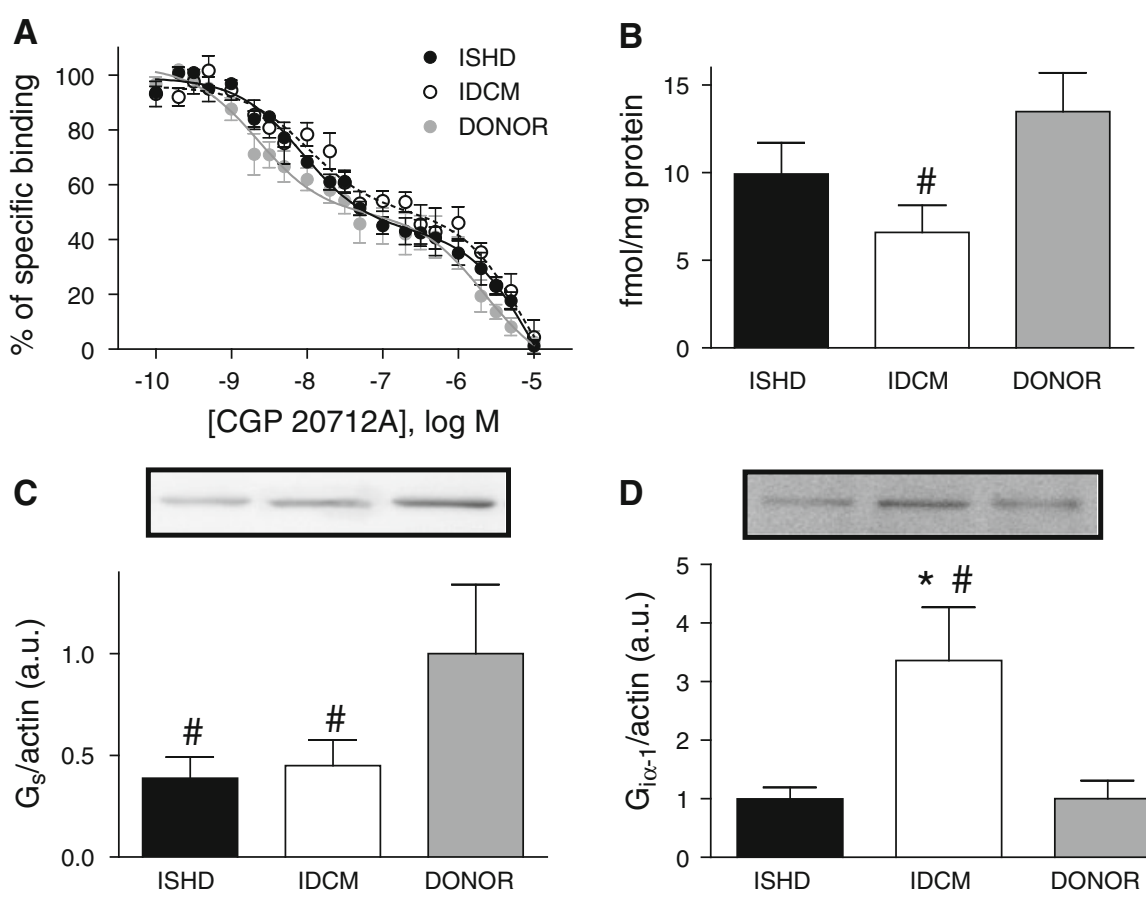

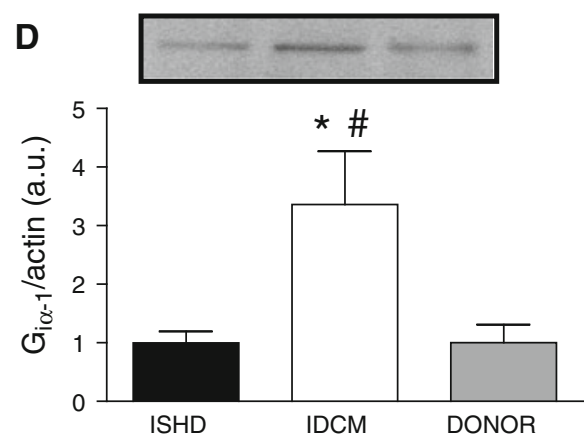

(Table 2).The $\mathrm{G}_{\mathrm{i} \alpha-3}$ expression level was not altered in patient groups (data are summarized in Table 2).

Myofilament and calcium handling proteins

ProQ Diamond phosphostaining was used to detect phosphorylation of myofilament proteins. Figure $2 \mathrm{a}$ shows ProQ Diamond-stained cardiac samples from ISHD, donor

Table 2 Protein analysis

\begin{tabular}{llll}
\hline & $\begin{array}{l}\text { ISHD } \\
(\mathrm{n}=9)\end{array}$ & $\begin{array}{l}\text { IDCM } \\
(\mathrm{n}=13)\end{array}$ & $\begin{array}{l}\text { Donor } \\
(\mathrm{n}=8)\end{array}$ \\
\hline GRK2 (a.u.) & $0.72 \pm 0.07^{\#}$ & $0.62 \pm 0.13^{\#}$ & $1.00 \pm 0.07$ \\
GRK5 (a.u.) & $1.92 \pm 0.23^{\#}$ & $1.33 \pm 0.19^{*}$ & $1.00 \pm 0.20$ \\
Gs (a.u.) & $0.39 \pm 0.10^{\#}$ & $0.45 \pm 0.13^{\#}$ & $1.00 \pm 0.30$ \\
Gi $\alpha$-1 (a.u.) & $1.00 \pm 0.20$ & $3.36 \pm 0.91^{\#, *}$ & $1.00 \pm 0.30$ \\
Gi $\alpha$-2 (a.u.) & $2.17 \pm 0.40^{\#}$ & $3.18 \pm 0.80^{\#}$ & $1.00 \pm 0.10$ \\
Gi $\alpha$-3 (a.u.) & $0.81 \pm 0.18$ & $1.19 \pm 0.30$ & $1.00 \pm 0.30$ \\
MLC-2P (a.u.) & $1.60 \pm 0.22^{\#}$ & $0.89 \pm 0.16^{*}$ & $1.00 \pm 0.07$ \\
PP-1 (a.u.) & $1.51 \pm 0.19$ & $2.45 \pm 0.35^{\#, *}$ & $1.00 \pm 0.40$ \\
Phospholamban & $1.43 \pm 0.14^{\#}$ & $1.55 \pm 0.08^{\#}$ & $1.00 \pm 0.04$ \\
$\quad$ (a.u.) & & & \\
SERCA2a (a.u.) & $0.99 \pm 0.07$ & $0.72 \pm 0.06^{\#, *}$ & $1.00 \pm 0.07$ \\
\hline
\end{tabular}

All signals in IDCM and ISHD samples were normalized to the averaged value observed in donor, which was set to 1 . GRK G-coupled receptor kinase, Gs G-stimulatory, Gi G-inhibitory, $M L C-2 P$ phosphorylated myosin light chain $2, P P-1$ protein phosphatase 1. a.u. arbitrary units, $n$ number of heart samples. ${ }^{*} P<0.05$ in Bonferronipost tests, IDCM versus ISHD; ${ }^{\#} P<0.05$, in Bonferroni-post tests, failing versus donor
(D) and IDCM myocardium separated on a gradient gel. The same gel was subsequently stained with SYPRO Ruby for analysis of total protein content (Fig. 2b). The ProQ Diamond stained gel shows lower endogenous phosphorylation of the PKA-target proteins cMyBP-C and cTnI in failing compared to -donor. Noteworthy, cTnI phosphorylation was significantly higher in ISHD compared to IDCM (Fig. 2c). In addition, phosphorylation of cMyBP-C was higher in ISHD compared to IDCM, though not significantly $(P=0.07)$. When the failing and donor were combined, a monovariate linear regression analysis revealed significant correlations between the ProQ Diamond-assessed phosphorylation status of cMyBPC and cTnI $\left(P<0.0001 ; \mathrm{R}^{2}=0.75\right)$ (Fig. 2d).

Higher PKA-mediated phosphorylation of cTnI (at Ser23 and Ser24, i.e., PKA sites) in ISHD compared to IDCM was confirmed in Western blotting (Fig. 3). Consistent with ProQ Diamond analysis of cTnI phosphorylation, the Western blots revealed significantly lower cTnI phosphorylation at PKA-sites in failing compared to donor.

Analysis of cTnI species separated by Phos-tag polyacrylamide gels revealed three bands upon staining of Western blots with a specific anti-cTnI antibody (8I-7) in donor, while only two bands were observed in the failing sample shown in Fig. 4a. The lower band was recognized by an antibody directed against cTnI unphosphorylated at PKA sites (22B11). The upper band was recognized by the phosphorylation-specific antibody which recognizes the PKA-sites Ser 23 and Ser 24. The second band on the blot is the mono-phosphorylated form of cTnI (Messer et al. 2009). Phos-tag analysis of samples from all groups are 
Fig. 2 a ProQ Diamondstained and b SYPRO-stained gel of ISHD, donor $(D)$ and IDCM samples. The ProQ Diamond stained gel clearly shows higher phosphorylation of cardiac cMyBP-C and cTnI in donor compared to the ISHD and IDCM sample. c The mean values are shown in the bar graph. Phosphorylation of cTnI was significantly higher in ISHD compared to IDCM. d A significant positive correlation was found between the phosphorylation status of cMyBP-C and cTnI $\left(P<0.0001 ; \mathrm{R}^{2}=0.75\right) . M H C$ myosin heavy chain, $c M y B P-C$ cardiac myosin protein $\mathrm{C}, c T n T$ cardiac troponin $\mathrm{T}, c T n I$ cardiac Troponin I, $M L C$ - 2 myosin light chain 2, $M$ molecular weight marker (PeppermintStick Phosphoprotein marker in which ovalbumin (OV) and $\beta$-casein $(\beta)$ are

phosphorylated). $* P<0.05$ in Bonferroni-post tests, IDCM versus ISHD; ${ }^{\#} P<0.05$, in Bonferroni-post tests, failing versus donor
A
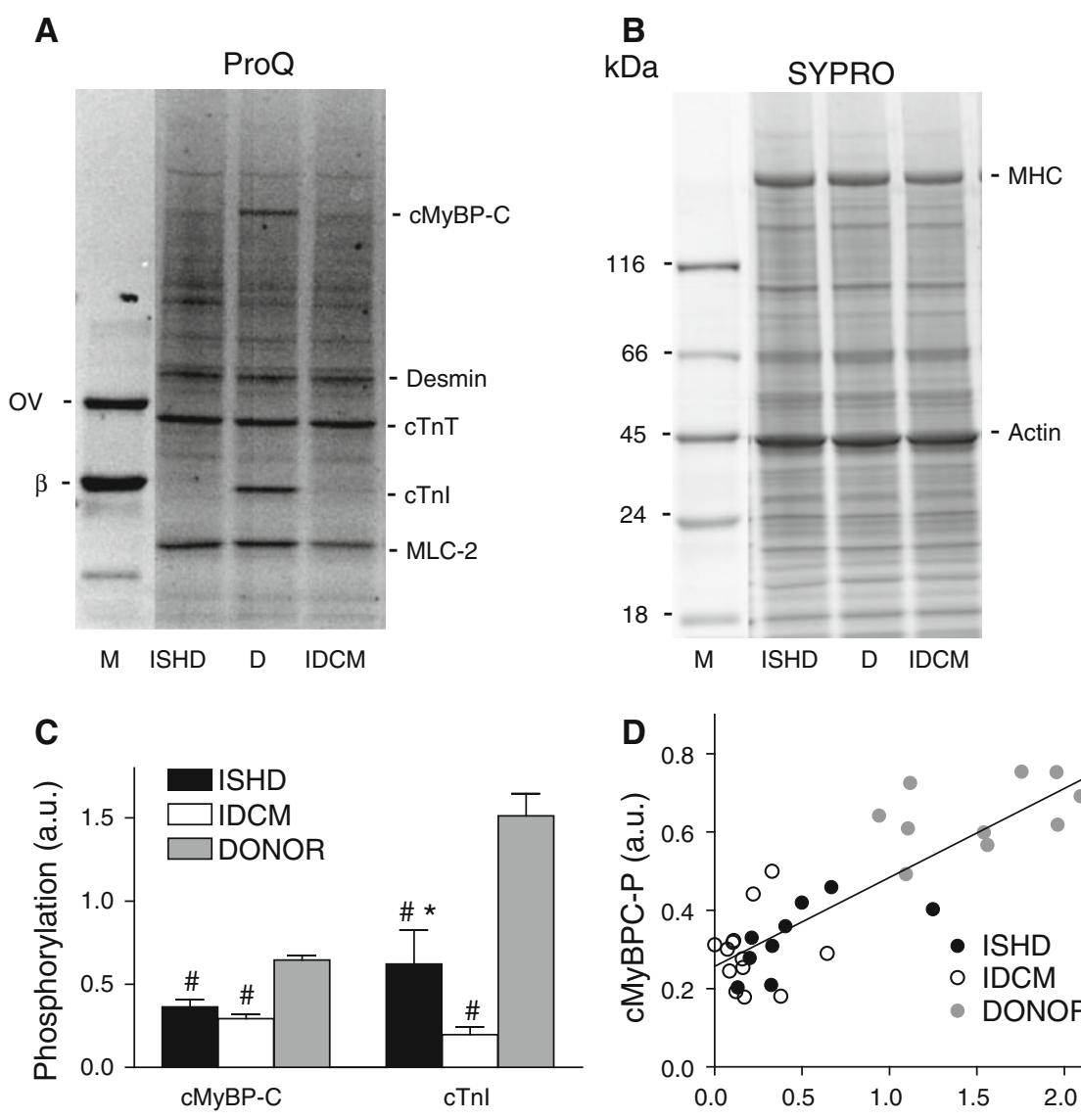

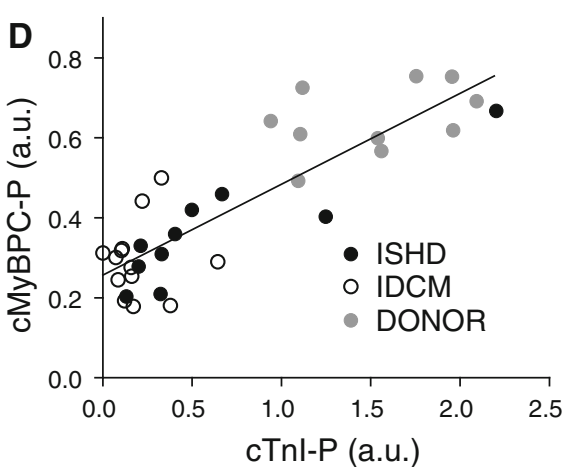

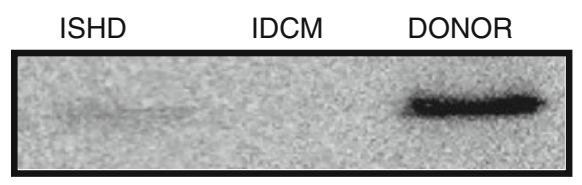

Phosphorylation at Ser 23/24

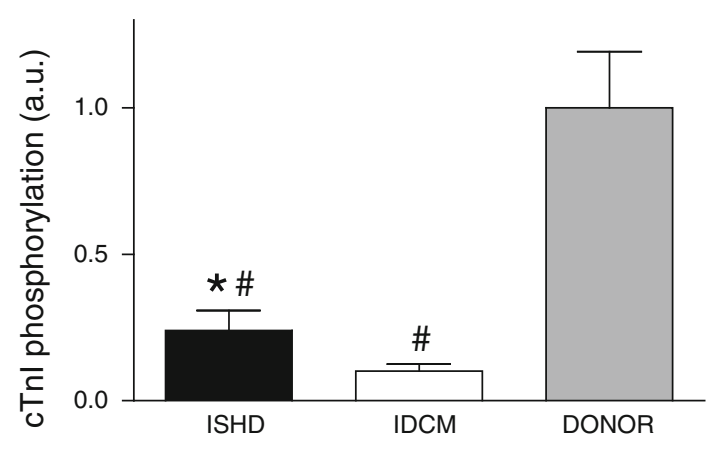

Fig. 3 Western blot analysis of troponin I (cTnI) phosphorylation at the PKA-sites Ser 23/24 revealed significantly higher cTnI phosphorylation in ISHD compared to IDCM, while cTnI phosphorylation was lower in both failing groups compared to donor. $* P<0.05$ in Bonferroni-post tests, IDCM versus ISHD; ${ }^{\#} P<0.05$, in Bonferronipost tests, failing versus donor shown in Fig. 4b. The distribution of the cTnI forms was significantly different among the three groups (Fig. 4c). The unphosphorylated form was highest in IDCM, while the bisphosphorylated form was highest in donor. A significant correlation was observed between phosphorylated cTnI on Phos-tag and cTnI phosphorylation analyzed by ProQ Diamond (Fig. 4d; $P<0.0001 ; \mathrm{R}^{2}=0.75$ ).

ProQ Diamond analysis also revealed higher phosphorylation of myosin light chain 2 (MLC-2) in ISHD compared to both IDCM and donor (Table 2), while there were no significant differences in phosphorylation of the other myofilament proteins, desmin and troponin $\mathrm{T}$ (data not shown). The difference in MLC-2 phosphorylation may be in part explained by differences in PP-1 expression. Western blot analysis of PP-1 revealed significantly higher PP-1 expression in IDCM compared to ISHD and donor (Table 2).

Western blot analysis showed increased phospholamban protein levels in IDCM and ISHD compared to donor and a significantly lower SERCA2a level in IDCM compared to both ISHD and donor (Table 2). The ratio of phospholamban over SERCA2a significantly differed among groups and was highest in IDCM. 
Fig. 4 a Phos-tag analysis of troponin I (cTnI) species revealed three $\mathrm{cTnI}$ bands in donor, of which the lowest band stained with an antibody directed against nonphosphorylated cTnI (22B11), and the highest band stained with the antibody specific for cTnI phosphorylation at PKA sites Ser23 and Ser24.

b Examples of cTnI species separated by Phos-tag analysis in different ISHD, IDCM and donor samples. c The distribution of cTnI species was significantly different among groups. d A significant correlation was observed between phosphorylated cTnI on Phos-tag and phosphorylated cTnI on Pro-Q Diamond-Stain $\left(P<0.0001 ; \mathrm{R}^{2}=0.75\right)$.

${ }^{\#} P<0.05$, in Bonferroni-post tests, failing versus donor
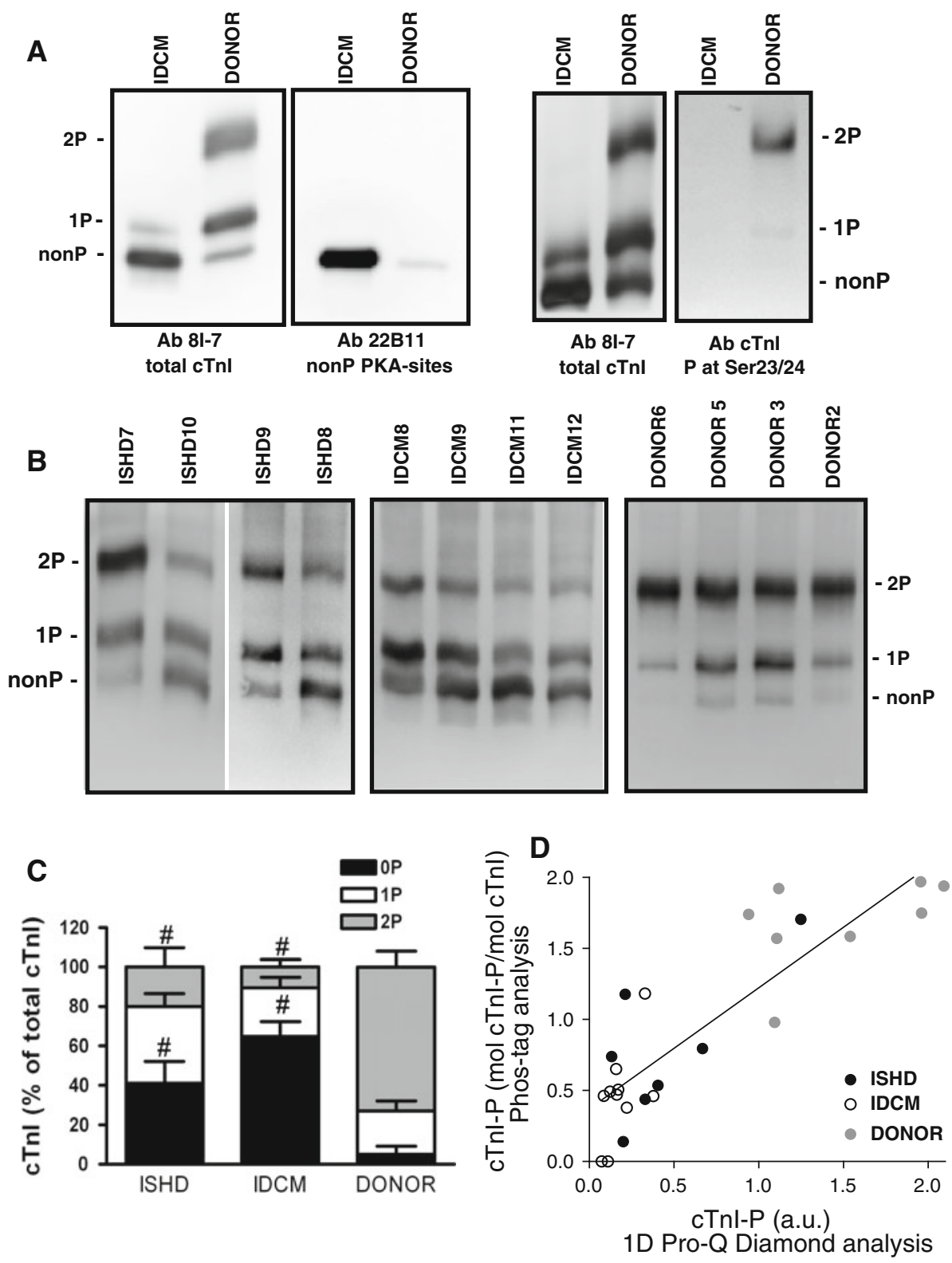

\section{Higher $\mathrm{Ca}^{2+}$-sensitivity in IDCM than in ISHD}

Force measurements were performed in single cardiomyocytes isolated from 8 IDCM hearts (42 cardiomyocytes), 8 ISHD hearts (27 cardiomyocytes) and 8 donor hearts (41 cardiomyocytes). Cross-sectional area of the cardiomyocytes determined at a sarcomere length of $2.2 \mu \mathrm{m}$ was significantly higher in IDCM $\left(556 \pm 44 \mu \mathrm{m}^{2}\right)$ and ISHD $\left(690 \pm 75 \mu \mathrm{m}^{2}\right)$ compared to donor (339 \pm $\left.26 \mu \mathrm{m}^{2}\right)(P<0.05$ in one-way ANOVA).

Maximal active tension ( $\left.\mathrm{F}_{\text {active }}\right)$ did not differ (Fig. 5a), while passive tension $\left(\mathrm{F}_{\text {passive }}\right)$ was significantly lower in IDCM and ISHD compared to donor (Fig. 5b).
Noteworthy, myofilament $\mathrm{pCa}_{50}$ was significantly lower in ISHD compared to IDCM (Fig. 5c, d). A significantly higher $\mathrm{pCa}_{50}$ was found in failing heart compared to donor (Fig. 5c, d). Moreover, the steepness of the sigmoidal force-pCa relationship (nHill) was significantly higher in ISHD (4.05 \pm 0.12$)$ compared to IDCM $(3.58 \pm 0.10)$ and donor $(3.70 \pm 0.14)$. A monovariate linear regression analysis revealed a significant correlation between $\mathrm{pCa}_{50}$ and phosphorylated cMyBP-C $\left(P<0.05 ; \quad \mathrm{R}^{2}=0.24\right)$ (Fig. 5e), while no significant correlation was found between $\mathrm{pCa}_{50}$ and ProQ Diamond-analyzed phosphorylated cTnI $\left(P=0.09 ; \mathrm{R}^{2}=0.12\right)$. Troponin I phosphorylation determined by Phos-tag analysis did significantly 
Fig. 5 a $\mathrm{F}_{\text {active }}$ did not differ among groups. b $\mathrm{F}_{\text {passive }}$ was significantly lower in failing groups compared to donor. c, d $\mathrm{pCa}_{50}$ was significantly higher in failing groups compared to donor. The $\mathrm{pCa}_{50}$ was significantly lower in ISHD compared to IDCM. e A significant correlation was observed between $\mathrm{pCa}_{50}$ and phosphorylated cMyBP-C $\left(P<0.05 ; \mathrm{R}^{2}=0.24\right)$. f A significant correlation was also found between $\mathrm{pCa}_{50}$ and Phos-tag analyzed cTnI phosphorylation $(P<0.01$; $\left.\mathrm{R}^{2}=0.43\right) . * P<0.05$ in Bonferroni-post tests, IDCM versus ISHD; ${ }^{\#} P<0.05$, in Bonferroni-post tests, failing versus donor
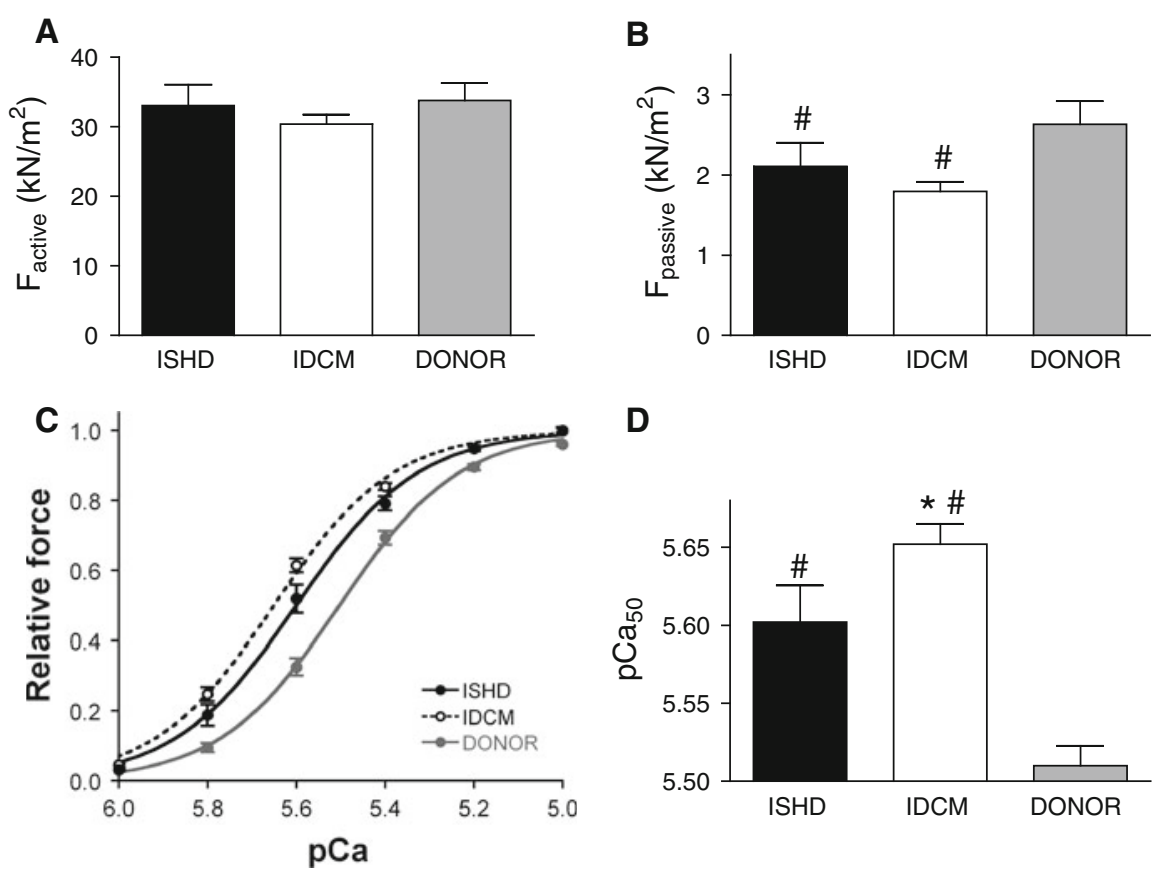

D
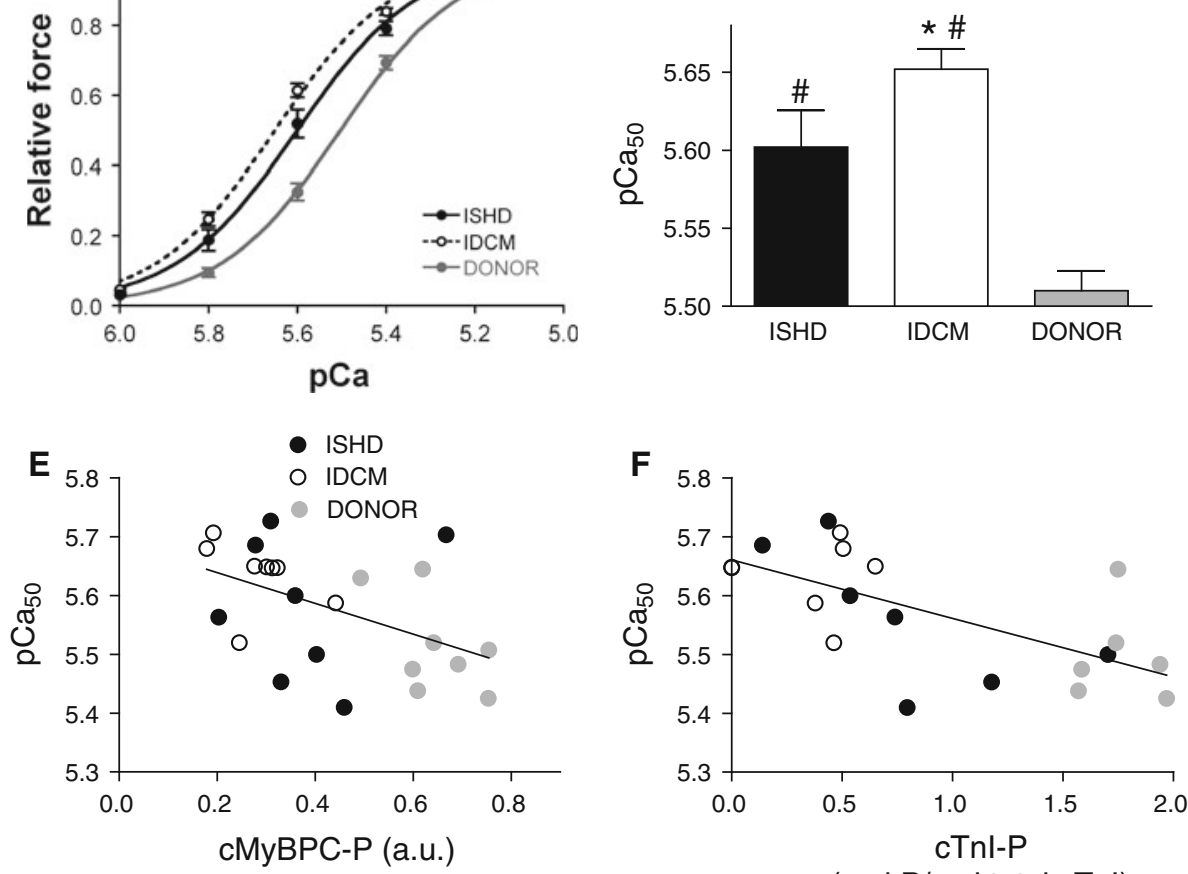

(mol P/mol total cTnl) correlate with $\mathrm{pCa}_{50}\left(P<0.01 ; \mathrm{R}^{2}=0.43\right)$ (Fig. 5f). The individual data per patient/donor for phosphorylation of the PKA target proteins, cMyBP-C and cTnI, and myofilament $\mathrm{Ca}^{2+}$-sensitivity are summarized in Table 1.

\section{Structural alterations}

Representative examples of light microscopy and electron microscopy images of LV sections from the three groups are shown in Fig. 6a and b, respectively. Cardiomyocyte diameter did not differ between ISHD and IDCM, but was significantly higher than observed in donor (Fig. 6c). Collagen volume fraction was significantly higher in IDCM compared to ISHD. Moreover, collagen volume fraction was significantly higher in both failing compared to donor (Fig. 6d). No differences were found in myofibrillar density between ISHD and IDCM, while it was significantly lower in both failing compared to donor (Fig. 6e).

\section{Discussion}

In the present study, diverse changes were found in the $\beta$ AR pathway in IDCM and ISHD patients. The results indicate that there are differences in the cellular structure and function between both patient groups. Compared to ISHD, IDCM was characterized by a more severe receptor $\beta A R$ down-regulation and increased $G_{i}$ expression, increased PP-1 expression, an enhanced reduction in protein phosphorylation, increased myofilament $\mathrm{pCa}_{50}$, reduced SERCA2a expression and higher collagen volume fraction. The data indicate that cellular dysfunction is more severe in IDCM than in ISHD patients.

Changes in components of the $\beta$-adrenergic pathway

In the present study, total $\beta \mathrm{AR}$ density was significantly reduced in IDCM compared to donor with intermediate 
A

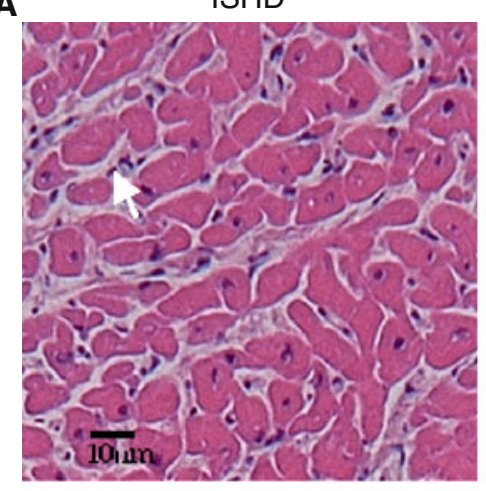

B
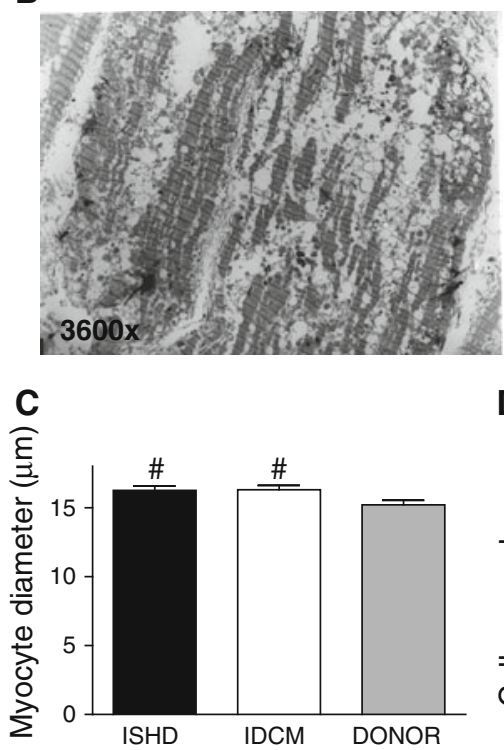

IDCM
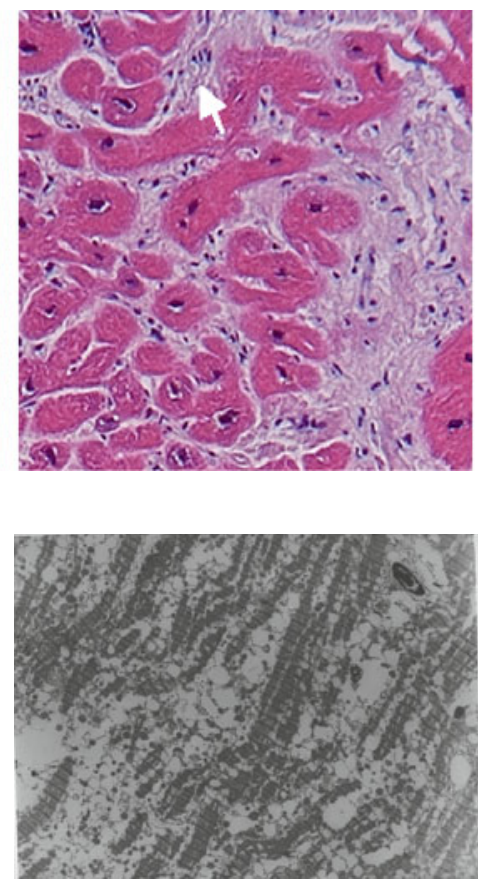

D

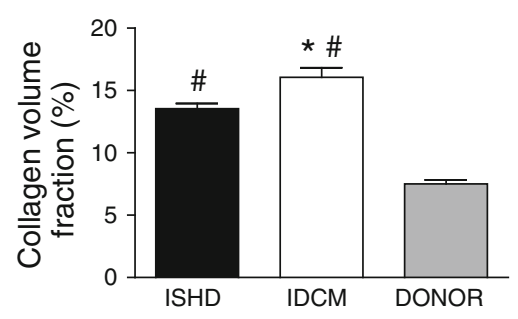

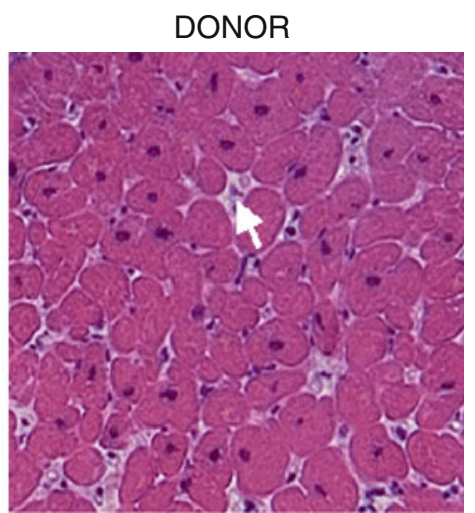

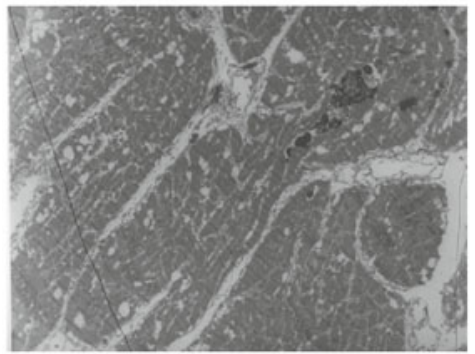

E

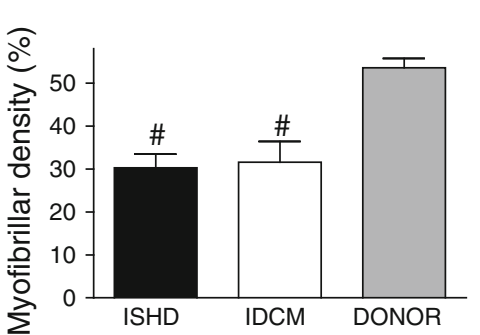

Fig. 6 Light microscopy (a) (hematoxylin-eosin stained; scale $10 \mu \mathrm{m})$ and electron microscopy (b; $3600 \times$ magnification) images of left ventricular sections from the three groups. Bar graphs showing cardiomyocyte diameter (c), collagen volume fraction (d) and myofibrillar density (e). A significant increase was observed in cardiomyocyte diameter and collagen volume fraction in both failing groups compared to donor. Analysis of cardiomyocyte diameter and collagen volume fraction were performed in 9 ISHD, 8 IDCM and 5 donor hearts. In addition, a significantly lower myofibrillar density was present in failing groups compared to donor. Analysis of myofibrillar density was performed in 8 ISHD, 6 IDCM and 5 donor hearts. The collagen volume fraction in IDCM was significantly higher compared to ISHD. ${ }^{*} P<0.05$ in Bonferroni-post tests, IDCM versus ISHD; ${ }^{\#} P<0.05$, in Bonferroni-post tests, failing versus donor. Arrow to indicate collagen

sympathetic tone in cardiac disease. In failing human tissue, Ungerer et al. $(1993,1994)$ showed increased GRK2 mRNA and activity in both ISHD and IDCM. In contrast, in the present study we observed lower GRK2 protein expression in both failing groups compared to donor, while GRK5 protein expression was significantly higher in ISHD compared to IDCM and donor.

The discrepant observation in GRK5 between ISHD and IDCM may reflect a difference in severity of disease, as Leineweber et al. (2005) observed an increase in GRK activity in right atrial tissue from patients at NYHA I and II, while in more severe stages (NYHA III and IV) GRK activity was similar as observed in controls. Interestingly, $\beta$ AR density did not differ in NYHA I and II and was 


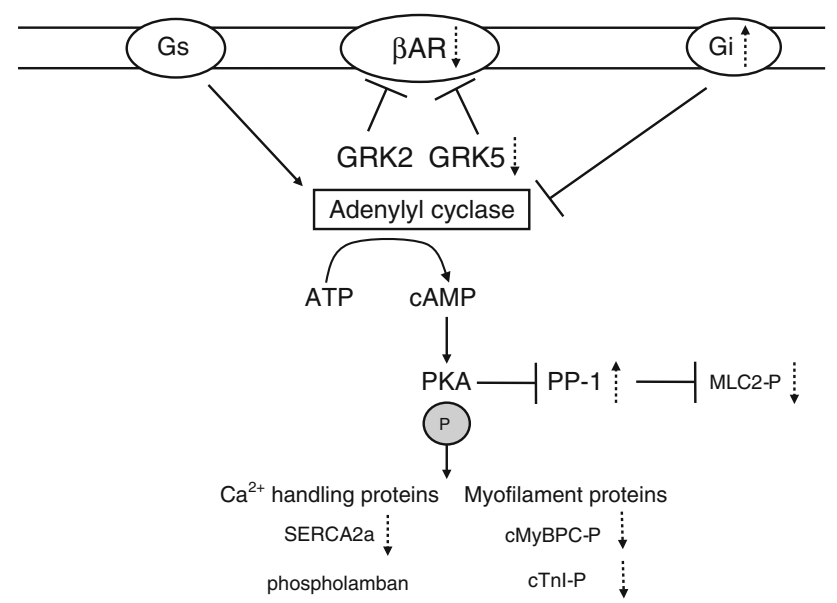

Fig. 7 Activation of $\beta$-adrenergic receptor pathway in the heart. Overall, changes were more severe in IDCM compared to ISHD, indicated by the dotted arrows, i.e., decrease or increase in IDCM compared to ISHD. $P$ Phosphorylation, $\beta A R \quad \beta$-adrenergic receptor, $G s$ G-stimulatory protein, $G i$ G-inhibitory protein, $G R K$ G-coupled receptor kinase, $\mathrm{Ca}^{2+}$ calcium, ATP adenosine tri-phosphate, $c A M P$ cyclic AMP, $P K A$ Protein kinase A, $P P-1$ protein phosphatase 1 , $M L C-2$ myosin light chain 2, $c M y B P-C$ cardiac myosin binding protein $\mathrm{C}, c T n I$ cardiac troponin I, SERCA2 $a \mathrm{SR} \mathrm{Ca}^{2+}$ ATPase

significantly reduced compared to controls in NYHA III and IV. These data are suggestive for a transient increase in GRK activity during the course of heart failure, and indicate that increases in GRK precede receptor down-regulation in the human heart. Accordingly, the high GRK5 expression and the lower reduction in $\beta$ AR density in ISHD compared to IDCM observed in the present study may reflect a less severe disease stage in ISHD, despite similar NYHA classification. The latter is further supported by the significantly higher expression of inhibitor G-protein in IDCM compared to ISHD.

More severe cellular phenotype in IDCM compared to ISHD

Analysis of sarcomeric protein phosphorylation revealed significant differences in the $\beta$ AR target proteins cMyBP-C and cTnI. Consistent with previous studies (El-Armouche et al. 2007; van der Velden et al. 2003; Messer et al. 2007, 2009; Copeland et al. 2010) phosphorylation of cMyBP-C and $\mathrm{cTnI}$ was significantly lower in both failing groups compared to donor, which has been explained by reduced PKA-mediated phosphorylation due to $\beta$ AR desensitization and down-regulation in cardiac disease (Wolff et al. 1996; van der Velden et al. 2003). Noteworthy, cMyBP-C and cTnI phosphorylation was lower in IDCM compared to ISHD, which fits the larger reduction in $\beta A R$ density and larger increase in $\mathrm{G}_{\alpha \mathrm{i}-1}$ expression observed in IDCM compared to ISHD. The higher myofilament $\mathrm{pCa}_{50}$ in IDCM compared to ISHD may be well explained by the significantly lower (PKA-mediated) myofilament protein phosphorylation observed in IDCM.

Interestingly, analysis of cTnI species using Phos-tag polyacrylamide gels showed that the difference in cTnI phosphorylation between IDCM and donor can be largely explained by a difference in the bis-phosphorylated form of cTnI (Fig. 4c). It is tempting to speculate that a difference in cTnI phosphorylation at PKA sites Ser 23/24 underlies the differences in $\mathrm{pCa}_{50}$ among groups. Although a significant correlation was found between myofilament $\mathrm{pCa}_{50}$ and phosphorylation status of cMyBP-C (Fig. 5e), the correlation with ProQ Diamond assessed cTnI phosphorylation did not reach statistical significance $(P=0.09)$. Noteworthy, cTnI phosphorylation determined with the Phos-tag assay did significantly correlate with myofilament $\mathrm{Ca}^{2+}$-sensitivity (Fig. 5f), indicating that Phos-tag analysis is a very accurate method to determine cTnI phosphorylation.

The correlation between cMyBP-C phosphorylation and $\mathrm{pCa}_{50}$ was stronger when cMyBP-C phosphorylation was combined with ProQ-Diamond assessed cTnI phosphorylation $\left(P=<0.05 ; \mathrm{R}^{2}=0.27\right.$; not shown). In a recent study in human myocardium we showed that myofibrillar targets of PKA, cMyBP-C and/or titin, play an important role in modulating the effect of cTnI phosphorylation on $\mathrm{pCa}_{50}$ in human myocardium (Kooij et al. 2010). Exchange of endogenous (mostly unphosphorylated) cTnI with PKAphosphorylated troponin complex did not reduce $\mathrm{pCa}_{50}$ in failing cardiomyocytes, in which endogenous cMyBP-C phosphorylation is low. Accordingly, our present data are compatible with a modulatory role for $\mathrm{cMyBP}-\mathrm{C}$ in force development at submaximal calcium concentrations in human myocardium.

In addition to the PKA targets, cTnI and cMyBP-C, phosphorylation of MLC-2 was significantly lower in IDCM than in ISHD. Dephosphorylation of MLC-2 occurs via PP-1, which was significantly higher in IDCM compared to ISHD. Although increased PP-1 expression may explain the relatively low MLC-2 phosphorylation in IDCM, it cannot explain the significantly lower MLC-2 phosphorylation in donor compared to ISHD, as PP-1 expression tended to be even lower in donor compared to ISHD. Other kinases/phosphatases most likely underlie the differences in MLC-2 phosphorylation observed between ISHD and donor myocardium and warrant future research.

Moreover, upon activation of $\beta \mathrm{AR}, \mathrm{PP}-1$ activity is depressed by PKA via phosphorylation of protein inhibitor 1 (I1) (Neumann et al. 1991). Thus, apart from increased PP-1 expression, perturbations in $\beta$ AR signaling will increase activity of PP-1, which may explain the lower MLC-2 phosphorylation in IDCM compared to 
ISHD. Increased activity and mRNA level of PP-1 has been reported previously in human IDCM (Neumann et al. 1997). Increased activity of PP-1 in a transgenic mouse model resulted in decreased myocardial contractility and dilated cardiomyopathy underscoring a detrimental role for PP-1 in heart failure (Carr et al. 2002). Increased PP-1 will also impair $\mathrm{Ca}^{2+}$-handling by dephosphorylation of phospholamban. The resulting reduction in $\mathrm{SR} \mathrm{Ca}^{2+}$ loading will be enhanced further by the reduction in SERCA2a expression in IDCM. Although several studies did not find differences in SERCA2a and PLB at mRNA levels between ISHD and IDCM (Arai et al. 1993; Flesch et al. 1996), our study showed reduced SERCA2a protein expression in IDCM, and increased phospholamban expression in both failing groups. Higher PP-1 expression and lower SERCA2a expression are indicative for a more severe cellular phenotype in patients with IDCM.

In line with previous studies (Anversa et al. 1986; Parodi et al. 1993; Weber 1989) we observed three structural alterations in end-stage heart failure: increased cardiomyocyte diameter (Fig. 6c), increased collagen volume fraction (Fig. 6d) and decreased myofibrillar density (Fig. 6e). While no difference was found in cardiomyocyte diameter and myofibrillar density between IDCM and ISHD, collagen volume fraction was significantly higher in IDCM compared to ISHD, which is in line with a previous study by Parodi et al. (1993).

\section{Adaptive cellular mechanism}

In agreement with previous studies (Makarenko et al. 2004; Nagueh et al. 2004; Neagoe et al. 2002) $F_{\text {passive }}$ in end-stage human heart failure was lower in comparison to donor. It has been proposed that the reduction in $\mathrm{F}_{\text {passive }}$ is due to a shift in titin isoform composition, from the stiff $\mathrm{N} 2 \mathrm{~B}$ to the more compliant N2BA isoform (Makarenko et al. 2004; Nagueh et al. 2004). In contrast, enhanced $F_{\text {passive }}$ was found in patients with less severe forms of heart failure (NYHA II-III) (Borbély et al. 2005, 2009; van Heerebeek et al. 2006), in which a similar shift in titin isoform composition was found as observed in endstage heart failure (i.e., more compliant isoform). The increased $F_{\text {passive }}$ at an early phase of heart failure was related with relative hypophosphorylation of the stiff $\mathrm{N} 2 \mathrm{~B}$ titin isoform (Borbély et al. 2009). Cardiomyocyte stiffness reflects the balance between isoform composition and isoform-specific phosphorylation status of titin. The shift to the compliant N2BA isoform during heart failure seems to be an adaptive mechanism to lower passive force (Makarenko et al. 2004), which may be maximal at end-stage heart failure.

\section{Conclusions}

Comparison of myocardium from patients with ISHD and IDCM end-stage HF revealed more severe cellular perturbations in patients with IDCM which are summarized in Fig. 7. Our data support previous studies in which transient changes were observed in the $\beta$ AR pathway. Increased GRK expression may be a primary event and possibly precedes the reduction in $\beta$ AR density, and the changes in expression of proteins involved in calcium handling and PP1. Noteworthy, Leineweber et al. (2005) showed that GRK5 was significantly lower in patients treated with $\beta$-blockers only in the relatively early stages of heart failure (i.e., NYHA I and II), in which GRK5 was higher compared to the end-stage of HF. Hence, the response to current treatment may depend on cause of cardiac disease, and may be less in patients with IDCM.

\section{Conflict of Interest None.}

Open Access This article is distributed under the terms of the Creative Commons Attribution Noncommercial License which permits any noncommercial use, distribution, and reproduction in any medium, provided the original author(s) and source are credited.

\section{References}

Anversa P, Ricci R, Olivetti G (1986) Quantitative structural analysis of the myocardium during physiologic growth and induced cardiac hypertrophy: a review. J Am Coll Cardiol 36(7):1140-1149

Arai M, Alpert NR, Mac Lennan DH, Barton P, Petiasamy M (1993) Alterations in sarcoplasmic reticulum gene expression in human heart failure a possible mechanism for alterations in systolic and diastolic properties of the failing myocardium. Circ Res 72(2): 463-469

Bers DM (2002) Cardiac excitation-contraction coupling. Nature 415(6868):198-205

Bohm M, Maack C (2000) Treatment of heart failure with betablockers. Bas Res Cardiol 95:I15-I24

Borbély A, van der Velden J, Papp Z, Bronzwaer JG, Edes I, Stienen GJM, Paulus WJ (2005) Cardiomyocyte stiffness in diastolic heart failure. Circulation 111(6):774-781

Borbély A, Falcao-Pires I, van Heerebeek L, Hamdani N, Edes I, Gavina C, Leite-Moreira AF, Bronzwaer JG, Papp Z, van der Velden J, Stienen GJM, Paulus WJ (2009) Hypophosphorylation of the Stiff N2B titin isoform raises cardiomyocyte resting tension in failing human myocardium. Circ Res 104(6):780-786

Brodde OE, Michel MC (1999) Adrenergic and muscarinic receptors in the human heart. Pharmacol Rev 51(4):651-690

Carr AN, Schmidt AG, Suzuki Y, del Monte F, Sato Y, Lanner C, Breeden K, Jing SL, Allen PB, Greengard P, Yatani A, Hoit BD, Grupp IL, Hajjar RJ, DePaoli-Roach AA, Kranias EG (2002) Type 1 phosphatase a negative regulator of cardiac function. Mol Cell Biol 22(12):4124-4135

Cheng Y, Prusoff WH (1973) Relationship between the inhibition constant $(K \mathrm{i})$ and the concentration of an inhibitor, which causes 50 per cent inhibition $\left(\mathrm{I}_{50}\right)$ of an enzymatic reaction. Biochem Pharmacol 22(23):3099-3108 
Cho H, Kehrl JH (2007) Localization of Gi alpha proteins in the centrosomes and at the midbody: implication for their role in cell division. J Cell Biol 178(2):245-255

Cohn JN, Levine TB, Olivari MT, Garberg V, Lura D, Francis GS, Simon AB, Rector T (1984) Plasma norepinephrine as a guide to prognosis in patients with chronic congestive heart failure. N Engl J Med 311(13):819-823

Copeland O, Sadayappan S, Messer AE, Stienen GJM, van der Velden J, Marston SB (2010) Analysis of cardiac myosin binding protein C in human heart muscle. J Mol Cell Cardiol 49:1003-1011

El-Armouche A, Pohlmann L, Schlossarek S, Starbatty J, Yeh YH, Nattel S, Dobrev D, Eschenhagen T, Carrier L (2007) Decreased phosphorylation levels of cardiac myosin-binding protein-C in human and experimental heart failure. J Mol Cell Cardiol 43(2):223-229

Elliott P, Andersson B, Arbustini E, Bilinska Z, Cecchi F, Charron P, Dubourg O, Kuhl U, Maisch B, McKenna WJ, Monserrat L, Pankuweit S, Rapezzi C, Seferovic P, Tavazzi L, Keren A (2008) Classification of the cardiomyopathies: a position statement from the European society of cardiology working group on myocardial and pericardial diseases. Eur Heart J 29:270-276

Flesch M, Schwinger RH, Schnabel P, Schiffer F, van Gelder I, Bavendiek U, Südkamp M, Kuhn-Regnier F, Böhm M (1996) Sarcoplasmic reticulum $\mathrm{Ca}^{2+}$-ATPase and phospholamban mRNA and protein levels in end-stage heart failure due to ischemic or dilated cardiomyopathy. J Mol Med 74(6):321-332

Hadcock JR, Malbon CC (1998) Down-regulation of $\beta$-adrenergic receptors: agonist-induced reduction in receptor mRNA levels. Proc Natl Acad Sci USA 85(14):5021-5025

Kentish JC, McCloskey DT, Layland J, Palmer S, Leiden JM, Martin AF, Solaro RJ (2001) Phosphorylation of troponin I by protein kinase A accelerates relaxation and crossbridge cycle kinetics in mouse ventricular muscle. Circ Res 88(10):1059-1065

Kinoshota E, Kinoshita-Kikuta E, Takiyama K, Koike T (2006) Phosphate-binding tag, a new tool to visualize phosphorylated proteins. Mol Cell Proteomics 5(4):749-757

Kooij V, Saes M, Jaquet K, Zaremba R, Foster DB, Murphy AM, dos Remedios C, van der Velden J, Stienen GJM (2010) Effect of troponin I Ser23/24 phosphorylation on $\mathrm{Ca}^{2+}$-sensitivity in human myocardium depends on the phosphorylation background. J Mol Cell Cardiol 48(5):954-963

Kranias EG, Garvey JL, Srivastava RD, Solaro RJ (1985) Phosphorylation and functional modifications of sarcoplasmic reticulum and myofibrils in isolated rabbit hearts stimulated with isoprenaline. Biochem J 226(1):113-121

Leineweber K, Rohe P, Beilfuss A, Wolf C, Sporkmann H, Bruck H, Jakob HG, Heusch G, Philipp T, Brodde OE (2005) G-proteincoupled receptor kinase activity in human heart failure: effects of beta-adrenoceptor blockade. Cardiovasc Res 66(3):512-519

Makarenko I, Opitz CA, Leake MC, Neagoe C, Kulke M, Gwathmey JK, del Monte F, Hajjar RJ, Linke WA (2004) Passive stiffness changes caused by upregulation of compliant titin isoforms in human dilated cardiomyopathy hearts. Circ Res 95(7):708-716

Messer AE, Jacques AM, Marston SB (2007) Troponin phosphorylation and regulatory function in human heart muscle: dephosphorylation of ser 23/24 on Troponin I could account for contractile defect in end-stage heart failure. J Mol Cell Cardiol 42:247-259

Messer AE, Gallon CE, McKenna WJ, dos Remedios CG, Marston SB (2009) The use of phosphate-affinity SDS-PAGE to measure the cardiac troponin I phosphorylation site distribution in human heart muscle. Proteomics Clin Appl 3:1371-1382

Muller A, van der Linden GC, Zuidwijk MJ, Simonides WS, van der Laarse WJ, van Hardeveld C (1991) Differential effects of thyroid hormone on the expression of sarcoplasmic reticulum $\mathrm{Ca}^{2+}$-ATPase isoforms in rat skeletal muscle fibers. Biochem Biophys Res Commun 203(2):35-40
Nagueh SF, Shah G, Wu Y, Torre-Amione G, King NM, Lahmers S, Witt CC, Becker K, Labeit S, Granzier HL (2004) Altered titin expression, myocardial stiffness, and left ventricular function in patients with dilated cardiomyopathy. Circulation 110(2):155-162

Neagoe C, Kulke M, del Monte F, Gwathmey JK, de Tombe PP, Hajjar RJ, Linke WA (2002) Titin isoform switch in ischemic human heart disease. Circulation 106:1333-1341

Neumann J, Gupta RC, Schmitz W, Scholz H, Nairn AC, Watanabe AM (1991) Evidence for isoproterenol-induced phosphorylation of phosphatase inhibitor-1 in the intact heart. Circ Res 69(6): $1450-1457$

Neumann J, Eschenhagen T, Jones LR, Linck B, Schmitz W, Scholz H, Zimmermann N (1997) Increased expression of cardiac phosphatases in patients with end-stage heart failure. J Mol Cell Cardiol 29(6):265-272

Niclauss N, Michel-Reher MB, Alewijnse AE, Michel MC (2006) Comparison of three radioligands for the labelling of human $\beta$ adrenoceptor subtypes. Naunyn-Schmiedeberg's Arch Pharmacol 374(3):99-105

Packer M (1995) Evolution of the neurohormonal hypothesis to explain the progression of chronic heart failure. Eur Heart $\mathbf{J}$ 16:F4-F6

Parodi O, De Maria R, Oltrona L, Testa R, Sambuceti G, Roghi A, Merli M, Belingheri L, Accinni R, Spinelli F (1993) Myocardial blood flow distribution in patients with ischemic heart disease or dilated cardiomyopathy undergoing heart transplantation. Circulation 88(2):509-522

Ungerer M, Böhm M, Elce JS, Erdmann E, Lohse MJ (1993) Altered expression of beta-adrenergic receptor kinase and beta 1-adrenergic receptors in the failing human heart. Circulation 87(2):652-654

Ungerer M, Parruti G, Böhm M, Puzicha M, DeBlasi A, Erdmann E, Lohse MJ (1994) Expression of beta-arrestins and beta-adrenergic receptor kinases in the failing human heart. Circ Res 74(2):206-213

Van der Velden J, Papp Z, Zaremba R, Boontje NM, de Jong JW, Owen VJ, Burton PB, Goldmann P, Jaquet K, Stienen GJM (2003) Increased $\mathrm{Ca}^{2+}$-sensitivity of the contractile apparatus in end-stage human heart failure results from altered phosphorylation of contractile proteins. Cardiovasc Res 57(1):37-47

Van Heerebeek L, Borbély A, Niessen HW, Bronzwaer JG, van der Velden J, Stienen GJM, Linke WA, Laarman GJ, Paulus WJ (2006) Myocardial structure and function differ in systolic and diastolic heart failure. Circulation 113(16):1966-1973

Vinge LE, Øie E, Andersson Y, Grøgaard HK, Andersen G, Attramadal H (2001) Myocardial distribution and regulation of GRK and beta-arrestin isoforms in congestive heart failure in rats. Am J Physiol Heart Circ Physiol 281(6):H2490-H2499

Wang X, Dhalla NS (2000) Modifications of $\beta$-adrenoceptor signal transduction pathway by genetic manipulation and heart failure. Mol Cell Biochem 214(1-2):131-155

Weber KT (1989) Cardiac interstitium in health and disease: the fibrillar collagen network. J Am Coll Cardiol 13(7):1637-1652

Wolff MR, Buck SH, Stoker SW, Greaser ML, Mentzer RM (1996) Myofibrillar calcium sensitivity of isometric tension is increased in human dilated cardiomyopathies: role of altered beta-adrenergically mediated protein phosphorylation. J Clin Invest 98(1):167-176

World Medical Association Declaration of Helsinki (1997) Recommendations guiding physicians in biomedical research involving human subjects. Cardiovasc Res 35:2-3

Zaremba R, Merkus D, Hamdani N, Lamers JMJ, Paulus WJ, dos Remedios C, Duncker DJ, Stienen GJM, van der Velden J (2007) Quantitative analysis of myofilament protein phosphorylation in small cardiac biopsies. Proteomics Clin Appl 1:1285-1290

Zhang R, Zhao J, Mandveno A, Potter JD (1995) Cardiac troponin I phosphorylation increases the rate of cardiac muscle relaxation. Circ Res 76(6):1028-1035 